\title{
THE MAJESTIC 8: ROLES OF SONG AS LYRICAL AUDIO OF LISTENING MEDIA
}

\author{
Armelia Nungki Nurbani \\ armelianungki@unipasby.ac.id \\ English Language Education Department, Faculty of Social Science and Humanities, Universitas PGRI \\ Adi Buana Surabaya
}

\begin{abstract}
The aim of this research was to find out the roles of songs in teaching listening at Senior High School. Teachers can use some media that are suitable with the condition of the class and students. For that reason, song is one of media that is familiar for students. Descriptive qualitative was the approach of this research. The data were derived from interview, observation and documentation. The interview were conducted by 7 participants consisting of 6 students and 1 teacher. The subject of this research was the twelve grade students of one of Senior High School in Surabaya. This study found 3 roles and 5 benefits of songs in teaching listening at Senior High School. The result of roles are 1) song is a cozy medium to teach listening. 2) song is used to entertain students in listening class. 3) song is used to motivate students to learn English in the classroom. Besides, the result of benefits are 1) the students can learn vocabulary and meaning. 2) the students can learn pronunciation. 3) the students can train their listening skill. 4) the students can enjoy the listening class. 5) the students became active and confident in the class. In conclusion, songs became one of good media in teaching listening because the students can feel comfortable, happy, and do not feel bored when they are in listening session. To all intens and purposes, there is a need to be conducted with having many participants for further research both different school or level. This is to get rich of the data in order to have more concrete data.
\end{abstract}

Keywords: Roles of song, listening media

\section{INTRODUCTION}

Creativity in teaching English as

foreign language is important for teachers

in order the students are interested in

teaching language in the class. Creative

teachers are facilitators who lead the

students become active learners in the

class. It is corresponding to Richards

(2013) that the creative teachers are

facilitators who are able to make effective

class. Understanding, encouraging, and developing creativity in the classroom is an international priority (Craft, 2011). Gardiner (2017) argues that the teacher's views of creativity and creative process are a fundamental importance to understanding how to teach the students. Creative teaching is useful for students to assist in improving original ideas and in creative thinking (Richards, 2013) especially in teaching listening, teacher 
should have a creative and many ideas to make a good atmosphere in listening class.

\section{Teaching listening is very} important into teaching English. Because this is the capital in receiving what has been say from the other people. Teachers need to encourage student participation by making experience in interesting and motivating activity. Then, the teachers should be supported the students to practice English as habit in order to make their English listening ability can be used to interact with other in daily life. Wallace (1992) argues that teaching listening is something to help a teacher in helping students to acquire the ability to understand the listening material. Teaching listening needs a collaboration among creative teachers, active students, and good strategy or method and the teacher guide the students to get information from the listening term itself. Therefore, teachers can use some media that are suitable with the condition of the class and students. One of media that is familiar for students that is songs. In respect to the use of songs, Sevik (2011) says that the song becomes fashionable media of teaching language in the classroom, especially teaching listening.

The examples of songs in this case were discussed not only as entertainment, but also as the teaching process in the teaching listening. There are several reasons why the songs are used. First, songs can change mood of the students. Second, songs can provide stimulation and entertainment. Third, songs can probably make students happy (Lopera, 2003). Teaching listening with songs media is very helpful for students, because it can make students feel interesting and make the students enjoy in listening class. Songs become one of the media that is good at teaching listening, because the students can feel comfortable, happy and do not feel bored when they are studying listening. Listen to their songs make students remember the lyrics of the songs. Harmer (2001) states that songs are 
powerful stimulus for students to increase their enthusiasm to learn. Songs can change atmosphere in the classroom and also entertain. Brand \& Lie (2009) identified that English as the second language from around the world and has a contribution in education related to song. The students when they are learning focus on this study is concerned with the roles of songs in teaching listening at Senior High School.

What the teacher should aware is not all songs can be given to the students. The songs were old and popular songs. The teacher chose old songs because he expected that the students rarely listened to them and it was a good technique to learn the vocabulary from the lyrics. The teacher would also choose any songs which were easy to understand. Related to the selection of songs, Lynch (2005) also states that there are three criteria in selecting songs: 1. Use songs that are popular with the students whenever possible; 2. Songs must have clear and understandable lyrics; 3. Songs should have an appropriate theme. Songs with any type of negative theme should be avoided. Some lyrics in songs may be offensive or inappropriate, so teacher should always be cautions when choosing the songs. Since most of the students were fascinated with pop songs and stars, the teacher paying attention to popular culture in foreign language teaching and learning and try to make the students to be students to be aware to that. Lynch (2005) states that popular songs are well known worldwide. Songs bring culture from other country to learn.

The study of the roles of songs in teaching listening has been done by Palacios \& Chapeton (2014), done in Public School in Colombia in which they founded on the students' responses to the use of songs in the EFL Classroom. The use of songs can share ideas, feelings in a comfortable, respect and friendly environment (Palacios \& Chapeton, 2014). 
However, Sevik (2011) conducted different research where he focused his study on teacher's views about using songs in the teaching English. This study has done in Primary School in Turkey. He stated that songs can be a media to teach listening and the use of songs in listening class have made the students feel happy and enjoy in the class, but teachers had a little difficulty in choosing the songs. (Sevik, 2011).

Although, there are some research related to the use of songs, the discussion from students and teachers' views have not been discussed in detail. Therefore, in this study it would be discussed the roles and benefit of songs from two perspective actors that are teachers and students' viewpoint. This paper focused on the roles of songs in teaching listening in one of Senior High School in Surabaya. This study found out how the roles of songs in teaching listening and why the students these are interested.

\section{RESEARCH METHOD}

Qualitative was the design of the study to get more data because the data taken from this study was from descriptive words, not from quantifications (Bryman, 2006). It means the researcher does not use numerical data. This qualitative study was a means to explore and understand the meaning that comes from individuals regarding and human behavior in a social context (Johnson \& Christensen, 2004). This study conducted descriptive qualitative research in obtaining data in the field.

The data was taken from transcribing of the interview and observation. The data was taken from the question and record answer interview from the participants. Question is usually icebreaker at the interview beginning. The next interview gives 5-6 questions that are the subject of the research question. The source of the data was the twelve grade. Creswell (2013) argues that the sample size depends on the qualitative design 
used. The participants in this research from

7 people, consist of 1 people English teachers in one of SMAN Surabaya, and 6 people consist of 3 female students, and 3 male students.

The data collection technique was collected by interview, observation, and documentation. The researcher conducted a face-to-face interview with the participants. The questions were unstructured and open-ended that are useful for getting opinions and viewpoint from the participants. After that, the researcher doing audio recording when interviewing participants. For the observation, immediately took the field to observe the behavior and activities of individuals at the research site. The result of the observation was adjusted to the result of the interview. The last, collecting the result of students' and teacher's transcript interview was the documentation.
Data analysis was taken from the interview. After getting the interview from all the participants, the researcher illustrated into the transcript. After that, coding was important to know the main answer of all participants. Thematic analysis was used to choose the theme of participants' answer. Brikci \& Green (2007) argues that thematic analysis is one way to identify the problem and the main theme chosen. Thematic is a method for descriptive qualitative projects. The first process and prepare the data results of transcribing interviews. Braun and Clark (2006) stated that thematic analysis is a provide a code with a set of specific themes and adjust to the data. This theme will relate to the research question and will display the responses or meaning within the data set. Braun and Clark (2006) identified doing thematic analysis there is 6 step-by-step guide, such as: familiarizing yourself with your data, generating initial codes, searching for themes, reviewing 
themes, defining and naming themes and the last producing the report.

The first, researcher must familiarize with the data. Familiarizing with the data was the first step after the researcher collects data and this related to analysis, the researcher must read the data repeatedly to be analyzed or transcribed data. For simplicity, the researcher made notes important points to code in some answers or participants' responses in the data.

The second step, researcher has read the result of the data carefully and familiarizing with the data, the researcher will generate initial codes. The researcher found an idea that would be used to code data and adjust it to the theme specified.

The third step, data have been initially coded and collated, and have a long list of the different codes have identified across the data set. In this case, the researcher analyzed the existing code. From this different theme code, how will it be made the overall theme of the research data?
The fourth step, researcher has devised a set of candidate theme, and it involved the refinement of those themes. In this step, there are 2 levels in the theme review. The first level, looking for extracts from the themes that have planned as candidates in the study. The theme was coherent or related to the study or not. Going to level 2, if there is a theme that is not appropriate or coherent, the researcher can reanalyze the extracts of the theme. If a theme is not appropriate, the researcher can replace with other candidate themes.

The fifth step, researcher had a satisfactory thematic map of the data. The researcher defined and further refine the themes that the researcher presented for the analysis, and analyzed the data within themes. In this step, the researcher began to determine the themes used and thought of the names of the themes briefly and can describe the content of the study.

The last step began when the researcher had a set of fully worked-out themes and involves the final analysis and 
p-ISSN: 2085-1383; e-ISSN: 2621-4156

wrote-up of the report. The themes used must be able to represent the data written.

The data from this research used triangulation to make the validity of the data. According to Denzin (1978) described four types of triangulation: methodological triangulation, data/source triangulation, theoretical triangulation, and investigator/analysis triangulation. The triangulation included the interview, observation, and documentation.

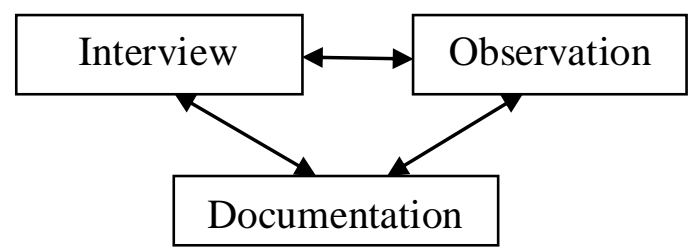

Figure 1. Triangulation

There are two arrows between interview, observation, and documentation showed in the figure above. So interview triangulated with observation, observation triangulated with documentation, and then documentation triangulated with the interview and so connected.

\section{FINDINGS AND DISCUSSION}

The Roles of Songs

There are three points which the roles of songs in teaching listening namely: song is a cozy medium to teach listening, song is used to entertain students in listening class, song is used to motivate students to learn English in the classroom.

1. Song is a Cozy Medium to Teach Listening

In the first research result, the role of songs is a cozy medium for teaching listening. It means that song is a medium containing message for teaching that can stimulate feelings, thoughts, and desires of students. Besides that, song is not only as a medium but also as entertainment in teaching and learning process. Teaching using songs is related to the aspect of listening skill because songs can be used to teaching listening and also entertain the student in the class. The data illustrated the condition in the following extract: 
Data $1 / \mathrm{Fz} 1$

The roles of songs as a teaching medium, not only for entertainment but also as a medium for me to learning listening.

Data $2 / \mathrm{Vn} 1$

The roles of songs as a teaching medium. I mean as a medium is a tool for me to learning English especially listening

Based on the data 1 and 2, songs

are media or tool for students to learn English specially to learn listening. Students can be entertained with a song media. Matched with Sevik (2012) that song has a lot of meaning, one of them is an enjoyful media. The song is included in the audio media because a song is related to the sense of hearing.

\section{Data 3/Nn1}

The roles of songs as a teaching medium to facilitate learning English. In the song, there are a lot of song lyrics that can later add to my vocabulary

Based on the data 3, song as a facility in learning English and students can be learned from song lyrics to add vocabulary. The researcher has observed in the class to directly see the learning process of students when using songs. The result of the observation that students more easily understand the material when using songs. In line with Kusnierek's (2016) research that Beside that from the students, a song also is a medium in teaching listening for the teacher. The data illustrated the condition in the following extract:

\section{Data 4/ Sn1}

The Song is media for me to teach material in teaching listening, so we not only listen to the song but we can also learn vocabulary and practice for students to say words from the lyrics of the song.

Based on the data 4, songs can be a medium for the teacher. This finding is in agreement with Sevik (2011) findings which showed that the song becomes fashionable media of teaching language in the classroom, especially teaching listening. When the teacher starts the class, the teacher sings a simple English song. This can help students learn vocabulary. There is a new vocabulary for them to understand. And it is easier to understand when using songs. Songs become the 
appropriate and cozy media for students to learn listening.

This is also supported from the observation; the researcher has seen the teacher teach students using songs in the classroom. The teacher always invites students to sing a song before in the beginning of the class. The purpose is to stimulate students to learn in the classroom.

\section{Song is Used to Entertain Students in}

\section{Listening Class}

The second finding was not only to entertain for students in listening class but also was used the students in the class out of class. The data illustrated the condition in the following extract:

\section{Data 5/ Rk1}

The role of a song is an entertainment. It is used in the class because there is a rhythm and the music fell comforted. So, we not only learn but also feel entertained in the class.

Data 6/ Vn2

The song is media, I mean that the song is media for me to learn English especially learning listening. Besides that, it is used as entertainment in order that we do not feel bored in English lesson in the class.

Based on the data 5 and data 6 , song can affect students' mood and can entertain. When the students felt bored songs can affect their mood in the class. They became more enthusiastic because they listen songs. They were entertained because songs have an element of tones and rhythms that can make students become relax and comfortable. This condition was in line with Sevik (2011) finding that use of songs in teaching listening class have made the students feel happy in the class.

That was also supported by observation from the researcher in the school. The researcher has seen when the students learn using songs and when they do songs. There were differences in this matter, for example, when the students were sleepy in the class when they were listening to songs. Besides that, the teacher also argues that teaching using songs is an 
interesting. The data illustrated the

condition in the following extract:

\section{Data $7 / \mathrm{Sn} 2$}

I think the most fun teaching is using songs. The students feel happy to learn. Besides that, they can also learn vocabulary, and how to pronounce of the words and lyrics in the songs

Based on the data 7, teaching using songs can make students learn vocabulary and pronunciation interestingly. It is proved from the observation that the researcher has seen that the teacher students interestingly using songs in the classroom. In addition, the songs not only made the students learn pronunciation or practice pronunciation easily, but they also learn English interestingly. Likely what Hidayat (2013) has already done that song also provides students an interesting way to meet their learning objectives.

\section{Song is Used to Motivate Students to}

\section{Learn English in the Classroom}

The third finding was that song is used to motivate students to learn English in the classroom. Songs can motivate those who listen to the lyrics of the songs. This finding was in agreement with Harmer (2001) finding that songs are a powerful stimulus for students to increase their enthusiasm to learn. The data illustrated the condition in the following extract:

\section{Data 8/ Rk2}

With the songs also make us more enthusiastic in the learning. From the rhythm of the songs that are used make us more excited

Data 9/ Df1

It can make me enthusiastic about learning in the class. So, I feel more enthusiastic to learn in the class if learning using songs. If the teacher has given the material continuously, it will make us feel bored in the class, don't be a spirit to listen explain the material from the teacher. So, learning using songs can be motivated to us be more enthusiastic. And the music from the songs is interesting

Based on the data 8 and data 9, songs gave advantages for students because the rhythm gave the effect of students feeling. The students do not feel bored in the class of the songs if the teacher only teaches the material with interesting way. That was also supported by the observation when the students learn using songs. Songs have rhythms and 
tones, making them more enthusiastic and feel happy to learn.

The teacher agreed that teaching listening using songs can motivate students. The data illustrated the condition in the following extract:

\section{Data 10/ Sn3}

My goal is to motivate students by using songs to learn. It can give students a sense of enthusiasm to start the lesson and so that students are not weak and sleepy in the classroom

Based on the data 10 , songs are used to motivate students to carry away with tones and rhythms of songs. Rhythms and tones of songs make students feel interesting in learning process. Lack of the students, interest in learning is characterized by a lack of enthusiasm, students' attention, and perseverance to learning. So, teaching using songs as a media for students to create enthusiasm for learning. Following Kusnierek's (2016) research, motivation in listening class plays a major role and songs can be a genuinely inspiring and special teaching media. That was in line with the students and teacher perception in data 8 to 10 .

That was also supported by the observation; the researcher has seen the teacher teach students using songs in the classroom. Students are more enthusiastic when they listen to the songs and give attention to the lyrics. Songs are effective learning media for students in the classroom. For the example, the teacher gives a question in the form of filling in an empty song lyric. And the students' enthusiasm to answer the question from the teacher. The students feel motivated to learn using songs.

\section{The Benefits of Songs}

There are five points which the benefits of songs in teaching listening namely:

\section{Intelligible Vocabulary and Meaning}

The benefits of songs were the students can learn vocabulary and meaning. Using songs to learn can understand vocabulary 
were more effectively. The data illustrated

the condition in the following extract:

\section{Data $11 /$ Fz2}

The benefits of songs are we can understand vocabulary from the meaning of the songs and we can also get new vocabulary in teaching listening

\section{Data $12 / \mathrm{Vn} 3$}

The benefits of songs that is I can know how to read vocabulary in teaching listening

Based on the data 11 and 12, learning using songs for students made them the vocabulary or the meaning of the words. Learning using songs was invited to improve listening skills and mastery of new vocabulary. The students were not only found out unfamiliar words in the dictionary but also made it easier for students to understand the meaning of songs' lyrics. The data illustrated the condition in the following extract:

\section{Data 13/ Rk4}

I know the meaning of the songs. Sometimes I don't know the meaning of the songs, but I can sing very well. I usually try to translate the lyrics of the songs using a di dictionary. If I find it difficult, I try to ask the teacher who teaches
Based on the data 13, songs can help students understand the meaning from songs' lyrics that were not understood. Also, the students can find out the meaning of songs in the dictionary or ask the teacher. So, the students can have a better understanding of the songs' meaning.

That was also supported by the observation, the researcher had seen the students when learning using songs. In the observation, the researcher saw students learning vocabulary from songs' lyrics that were not understood. Also, the students understand the meaning of songs that are not understood by asking the teacher or find out for the meaning of the songs in the dictionary.

The teacher agreed that teaching listening using songs can be learning vocabulary. The data illustrated the condition in the following extract:

Data 14/ Sn4

This can also add vocabulary, surely in the songs, there is a new vocabulary for them to understand. And it's easier to understand when teaching using songs 
Based on the data 14 , teaching using songs can help students learn vocabulary from the lyrics of the song. The students can learn many words of songs' lyrics, they can add vocabulary that is rarely or unfamiliar. Then, the teacher argued that the students can learn the meaning of songs. The data illustrated the condition in the following extract:

\section{Data $15 / \operatorname{Sn} 5$}

I think it makes easier for students to understand the meaning of words. So, they can know the meaning of songs that are not understood. If they don't understand, they can ask me or look for it directly in the dictionary

Based on the data 15, teaching using songs can also help students to understand the meaning of songs. That was also supported by the observation, the researcher had seen the teacher to teach students using songs in the classroom. In this observation, the teacher gave songs that were heard by students. From the lyrics of the song, the students learned vocabulary and also the students understand the lyrics of the songs.

Following Kusnierek's (2016) and Sevik's (2011) research, the way of using song did truly impacts the memorization of students' vocabulary. Redundancy of melodies seem to offer assistance the students to put the words into long-term memory since things rehashed different times are nearly incomprehensible to disregard. That was in line with the students and teacher perception in data 11 to 15 .

\section{Applicable Pronunciation}

The selection of songs with a clear and correct pronunciation can also familiarize to listen in learning. The data illustrated the condition in the following extract:

\section{Data 16/ Nn2}

The first one can practice my word pronunciation when speaking English. Sometimes I don't know how to pronounce the words or lyrics of the songs. So, I can learning pronunciation using songs 
Based on the data 16 , songs

helped the students' pronunciation in English when they are speaking. The students can practice pronunciation of words from song lyrics correctly because the students got more pronouncing exercise of the English words. In accordance with Mulatsih (2015), the result of her study appeared critical advance in students' pronunciation because they were more fascinated when learning pronunciation using song. This is also supported by the observation; the researcher had seen students when learning using songs. The first students listen to the lyric of the songs spoken by the teacher. After that the students repeat again, it is helpful for students to pronouncing the English words.

\section{Trainable Listening Skills}

In the third research finding, the benefits of songs are the students can train their listening skills. The data illustrated the condition in the following extract:
Data 17/ Az2

The benefits of songs in learning are to train the ability or listening skills. I can train listening skills using songs. Listen to English sentence from songs lyrics

\section{Data 18/ Nn3}

The benefits of songs can train my listening skills. I became more familiar with vocabulary or pronunciation using English, and I became more understanding

Based on the data 17 and data 18 , those were true that songs can train students listening skill. Students can practice the sentences of the song lyrics and also rewrite the lyrics of the song. Same as Kusnierek's (2016) research result that when students always listen and practice many times, the sentence of practices make perfect is not impossible come to the students.

\section{Likable Listening Class}

The songs helped the students to vent feeling that was held in the heart, making the students more relieved and more able to accept what is happening. This finding was in agreement with Lopera (2003) findings which stated that there were several reasons why the songs are used. 
First, songs can change the mood of the students. Second, songs can provide stimulation and entertainment. Third, songs can probably make students happy. The data illustrated the condition in the following extract:

Data 19/ Df3

Using songs can make me not bored in the classroom. When I feel that English is sometimes boring, it is more interesting and fun to sing songs.

Data 20/ Df4

Using songs make me happy. I am happy because I can sing together with friends and can also make us relaxed and don't be bored in the classroom. I am not only learn from the lyrics in the songs but also have fun too. Sing together so it's fun teaching to using songs

Data 21/ Rk5

Using songs make me happy, and enjoyed learning. With songs also makes us more enthusiastic in learning. From the rhythm of the songs that are used make us more exited

Based on the data 19, data 20, data 21 songs can make the atmosphere comfortable and enjoyable. This finding was supported the previous study conducted by Palacios \& Chapeton (2014) who said that the use of songs can share idea, feelings in a comfortable, respect and friendly environment. The students interested and entertained if they learn listening to using songs. Usually learning without using media make students very bored in the class but with a song, students do not feel bored, happy, and enjoy when they learn. This was also supported by the observation, the researcher had seen that the students were not happy to learn, got out of the class, so that learning using songs made the comfortable. Students felt happy by singing with their friends.

\section{Growable into Active and Confident}

In the fifth research finding the benefits of songs is the students become active and confident in the listening class.

The data illustrated the condition in the following extract:

Data 22/ Df5

I am more active in teaching and often become more confident to get good grades from my teacher

Data 23/ Nn4

I also feel embarrassed like that. Because, sometimes I forget the lyrics or I do not know how to read 
or pronounce the word. But this also had a positive impact on me. I became more confident in the class

Based on the data 22 and data 23 songs can make the students active and confident. When the students learning listening, students invited to come forward and sing. This helped students who were initially passive become active and appear more confident in front of the class. Then the teacher argued that the students become active and confident in the listening class. The data illustrated the condition in the following extract:

Data 24/ Sn6

Students who are initially quiet and passive become more active and brave to sing English

Based on the data 24 songs can make the students active in the class. When the teacher using songs as media in teaching, the teacher asked the students to check the progress one by one in front of the class to sing so that this can grow their activity in the classroom.

\section{Data 25/ Sn7}

This can grow their confidence. When I asked them to sing the song again, they would dare to sing the song with confidence. And that in my opinion is a very good change.

Based on the data 25, songs can make the students confident in the class. The teacher using songs can increase students' confidence. Students can learn to sing without shame. This was great for changing students' attitudes in the classroom while learning listening. In accordance with Kusnierek (2016) that songs are a culminate source for fortifying dialogs. Students can be active and confident individual by starting conversation with another in sets or in little bunches what happened within the song and after that share their conclusions with the rest of students.

\section{CONCLUSION}

Based on the research results and discussions, the result of this research was shown that this section consists of two parts. The first part discusses about the roles of songs in teaching listening and the second part discusses the benefits of songs in teaching listening. For the first part, the data was classified in the roles of songs in teaching listening: song is a cozy medium 
to teach listening, song are used to entertain students in listening class, and song are used to motivate students to learn English in the classroom. For the second part, the data was classified in the benefits of songs in teaching listening: the students can learn vocabulary and meaning, the students can learn pronunciation, the students can train their listening skill, the students can enjoy in the listening class, and the students became active and confident in the listening class.

Furthermore, the secondary data which was collected by using observation also showed that the students who were in listening class would be interesting and enjoying when the teacher used songs as lyrical audio as listening media. Students can also practice a listening skill from songs' lyrics.

Therefore, teaching and learning using songs as lyrical audio have many roles and benefits for teacher and students in teaching listening, especially achievement at twelve grade students of one of Senior High School in Surabaya.

\section{REFERENCES}

Brand, M. \& Li, X. 2009. Effectiveness of Music on Vocabulary Acquisition, Language Usage, and Meaning for Mainland Chinese ESL Learners. Contribution to Music Education, Vol. 36 (1), 73-84.

Braun, V., \& Clarke, V. 2006. Using Thematic Analysis in Psychology. Qualitative Research in Psychology, Vol. 3 (2). 77-101.

Bricki, N., \& Green, J. (2007). A Guide to Using Qualitative Research Methodology. United Kingdom: MSF Field Research.

Bryman, A. 2006. Integrating Quantitative and Qualitative Research: How is it Done?. SAGE Journals, Vol. 6 (1), 97-113.

Craft, A. (2011). Creativity and Educating Future: Learning in a Digital Age: Stoke on Trent. UK and Sterling USA: Treatham Books.

Creswell, J.W. (2013). Qualitative Inquiry and Research Design: Choosing Among Five Approaches (3rd edition). Thousand Oaks, CA: Sage.

Denzin, N. K. (1978). The Research Act: A Theoretical Introduction to Sociologial Methods (2nd ed). New York: McGraw-Hill.

Gardiner, P. 2017. Playwriting and Flow: The Interconnection Between Creativity Engagement and Skill Development. International Journal 
of Education \& the Arts, Vol. 18 (6), $1-24$.

Harmer, J. (2001). The Practice of English Language Teaching. Essex, England: Longman.

Hidayat, A. 2013. The Use of Songs in Teaching Students' Listening Ability. Journal of English and Education, Vol. 1 (1), 21-29.

Johnson, B., \& Christensen, L. (2004). Educational Research: Quantitative, Qualitative, and Mixed Approaches. Boston: Pearson.

Kusnierek, A. 2016. The role of music and songs in teaching English vocabulary to students. World Scientific News, Vol. 43 (1), 1-55.

Lopera, S. 2003. Useful Ideas When Taking Songs to a Class. Ikala: Revista de Language y Cultura, Vol. 8 (14), 135-149.

Lynch, M, L. (2005). Using Popular Song to Improve Language Listening Comprehension Skills. Retrieved on November 29, 2011 from

http://ezinearticles.com/?Using-PopularSongs-to-ImproveLanguageListening-Comprehension$\underline{\text { Skills\&id }=104984}$
Mulatsih, D. 2015. Pronunciation Ability by Using English Song in Indonesian Student of Unswagati Cirebon. Academic Journal Perspective. Vol. 2 (2), 294-299.

Palacios, N., \& Chapeton, C, M. 2014. Students' Responses to the Use of Songs in the EFL Classroom at a Public School in Bogota: A Critical Approach. Giest Education and Learning Research Journal, Vol. (9), 9-30.

Richards, J. C. 2013. Creativity in Language Teaching. Iranian Journal of Language Teaching Research, Vol. 1 (3), 19-43.

Sevik, M. 2011. Teachers Views About Using Songs in Teaching English to Young Learners. Educational Research and Review, Vol. 6 (21), 1027-1035.

Sevik, M. 2012. First Step to Effective Listening: "Listen and Show" Songs. International Journal of English and Education, Vol. 1 (1), 9-19.

Wallace, C. (1992). Language Teaching of Schemata for Teacher Education. New York: Oxford University Press. 